\title{
Field Hockey Skill Tests Construction and Validation on Female Hockey Players
}

\author{
Dr Inderpreet Kaur Nanda ${ }^{1 *} \quad$ Dr Gursharan Kaur ${ }^{2}$ \\ 1.Assistant Professor, S.G.T.B. Khalsa College, University of Delhi, Delhi-110007 \\ 2.Assistant Professor, Mata Sundari College, University of Delhi, Delhi-110002
}

\begin{abstract}
Hockey is a team-game in which the different players have to perform the different types of skills to overcome the opponent, each members of team have to perform best, to achieve success. In any sports discipline assessment of player can be done by subjective or objective means. Skill tests of relevant sports discipline helps in the objective assessment of the player. Sports skill tests are designed to measure the basic skills used in the playing of a specific sport. The degree of perfection of sport skills obviously varies significantly with the level and gender of the players. The mastery of the fundamental skills in any game results in the high level performance. Norms are necessary if the test scores are to be adequately interpreted. The type of test is selected depending upon the purpose of the test and characteristics of the group to be tested." The aim of the present study was to construct and standardize the fundamental skill tests for the game of field hockey which contribute towards performance of the players. The objectives of the study measures the selected skills and performance and further establishing validity, reliability and objectivity the selected skill. Also the percentile norms and Hull scale for selected skill tests was constructed for field hockey female players. The study is delimited to 5 skills hitting, pushing, dribbling, passing and stopping, also female hockey players of inter-college level age ranged between 17 to 25 years with average age of 21 years were selected. The data collected were subjected to various statistical analysis. Product Moment Correlation was used to find out inter - relationship among all the skill test items, Factor Analysis was applied in which, significant factors responsible for variance and dominant were extracted through Principal Component Analysis, The reliability of the filtered skill test items was computed by test retest method and Finally norms were developed using percentiles and Hull Scale. "The result reveals that there was inter-relationship between the performances of selected test items. The knowledge evolved in this study is directly helpful to coaches, trainers, trainees and teachers of Hockey and also selection committee of Field Hockey at different levels. This contribution will enrich the overall game performance in Indian Field Hockey.
\end{abstract}

Keywords: Field Hockey, Norms, Performance, Skills

DOI: $10.7176 / \mathrm{JTHS} / 58-02$

Publication date:August $31^{\text {st }} 2021$

\section{Introduction}

In sports and games the performance is inevitable. Nowadays, the nature of sports and games has gone through tremendous radical changes in international arena. Identification of effective players is becoming a crucial, because day by day the games have become highly competitive. In sports and games, performance of players is judged by competition results. Apart from competition, the assessment of a player in any sports discipline can be done either by subjective or objective means. The test, measurement and evaluation concept was in existence in physical education for past several years. Many extensive research works have been done in these areas. Skill tests require an environment similar to the game environment and standardized procedures for administration. The validity of skill tests is judged to some extent on the consistency between testing and performing environments. A skill of the game plays a very vital role in the success of modern hockey. Each skill is having its own importance and application to different situation. A hockey player must master over skills to prove his proficiency. Nowadays, hockey matches are won by those teams who are more skilled. The perfection of these skills will have a direct impact on the total performance in the game. High level of performance of a hockey player depends upon fundamental skills. It is recognized that among the fundamentals, ability to dribble the ball, ability to hit, ability to push, ability to stop and ability to pass, are of primary importance for high level of performance. Hence, from the fundamental skill a few selected skills namely Dribbling, Hitting, Stopping, Pushing and Passing was selected as the variables for the study for construction of norms.

Therefore, looking into the importance of fundamental skills in field hockey, the research scholar after having gleaned the literature and series of discussion with the supervisor, advisory committee and other experts in the field, decided to study the and construct skill tests for female hockey players.

\subsection{Objectives}

Keeping in view the background, need, purpose of the study, the researcher has chalked out the following major objectives. 
(a.) To identify different skills which are important for the performance in field Hockey.

(b.) To identify the skills tests to measure the selected skills of the player.

(c.) To establish the reliability of the selected test skill.

(d.) To establish the validity of the selected skill tests.

(e.) To establish the objectivity of the selected skill tests.

(f.) To construct the percentile norms for the fundamental skills in field hockey.

(g.) To construct Hull Scale for selected fundamental skills of field hockey

\section{Procedure \& Methodology}

\subsection{Research Methodology}

A pilot study was conducted on 30 female field hockey players of University of Delhi of age ranging from 17 to 25 years with a minimum participation in the Inter-college tournaments. For purpose of the pilot study, a set of 15 skill test items were constructed and run on the subjects.

The system of scoring was based on number of points earned by the player in each skill test. The point system was employed for the scoring as this system helps to make assessment more easy, objective and easy to interpret. Face validity was claimed for the test which was constructed by the advice and recommendations of the experts in hockey and by reviewing the related literature in the game. Through ground run of 15 skills test items for five fundamental skills the administrative feasibility of each test items was assessed and skill test items name was finalized. The 15 skills test items finalized for further testing were as follows:

\section{TABLE 1}

Skill Tests for Five Fundamental Skills

\begin{tabular}{|c|c|c|}
\hline \multirow{2}{*}{ SKILLS } & TEST NO. & NAME Of TEST ITEMS \\
\hline \multirow{3}{*}{ HITTING } & 1 & 'D' Hitting Accuracy Test \\
\cline { 2 - 3 } & 2 & Multi Target Hitting Test \\
\cline { 2 - 3 } & 3 & Long Distance Hitting Accuracy Test \\
\hline \multirow{3}{*}{ STOPPING } & 1 & Restricted Area Stopping Accuracy Test \\
\cline { 2 - 3 } & 2 & Goal Stopping Accuracy Test \\
\cline { 2 - 3 } & 3 & Multi Side Stopping Accuracy Test \\
\hline \multirow{3}{*}{ DRIBBLING } & 1 & Straight Zig-Zag Cone Dribbling Test \\
\cline { 2 - 3 } & 2 & 'W' Zig Zag Cone Dribbling Test \\
\cline { 2 - 3 } & 3 & Circle Zig-Zag Cone Dribbling Test \\
\hline \multirow{3}{*}{ PUSHING } & 1 & Goal Accuracy Push Test \\
\cline { 2 - 3 } & 2 & Multi Target Push Accuracy Test \\
\cline { 2 - 3 } & 3 & 'D' Pushing Accuracy Test \\
\hline \multirow{3}{*}{ PASSING } & 1 & Multi Side Passing Accuracy Test \\
\hline & 2 & One Touch Accurate Cone Passing Test \\
\hline & 3 & Accurate Interchange Passing Test \\
\hline
\end{tabular}

\subsection{Statistical Techniques}

In the present study, the data was collected as per the schedule in two phases from the regular female hockey trainees of Delhi-NCR, from the selected subjects. The data for 5 skills consisting of 15 test items was collected on 50subjects of Delhi University colleges and factor analysis, partial and multiple correlations was computed on the data to filter the test items. After factor analysis of the data scientific authentication of the filtered eight skill test items was computed on 50 subjects. For development of norms on selected skill test after scientific authentication, 200 subjects of Delhi-NCR female hockey players who had past three years of experience in field hockey. Finally norms were developed using percentiles and Hull Scale.

\section{Results \& Discussion}

The construction of the Field Hockey skill tests was based on the administration of fifteen skill test items to the sample of 200 female Field Hockey players excluding goal keeper randomly selected from various colleges \& hockey clubs \& academies \& SAI centers of Delhi-NCR, India. The study was based on true randomized group design and the fifteen skill test items that significantly correlated were subjected to Factor Analysis. The factor analysis yielded seven factors. 
TABLE 2

Varimax Method

Rotated Factor Analysis of Selected Skill Test items

\begin{tabular}{|c|c|c|c|c|c|c|c|c|}
\hline & \multicolumn{7}{|c|}{ Varimax Method (Rotated Factor Loading ) } & \multirow{2}{*}{$\begin{array}{l}\text { Commun } \\
\text { alities }\end{array}$} \\
\hline & F1 & F2 & F3 & F4 & F5 & F6 & F7 & \\
\hline 'D' Hitting Accuracy Test & & & & & & & .422 & .558 \\
\hline Multi Target Hitting Test & & & .635 & & & & & .608 \\
\hline Long Distance Hitting Test & & & -.745 & & & & & .598 \\
\hline $\begin{array}{c}\text { Restricted Area Stopping Accuracy } \\
\text { Test }\end{array}$ & & & & .833 & & & & .724 \\
\hline Goal Stopping Accuracy Test & & & & & & .719 & & .541 \\
\hline Multi Side Stopping Accuracy Test & & & & & .816 & & & .696 \\
\hline $\begin{array}{c}\text { Straight Zig-Zag Cone Dribbling } \\
\text { Test }\end{array}$ & & & & & & -.301 & & .621 \\
\hline 'W' Zig Zag Cone Dribbling Test & & .680 & & & & & & .518 \\
\hline Circle Zig-Zag Cone Dribbling Test & & & & & & & & .519 \\
\hline Goal Accuracy Push Test & & & & & & & & .592 \\
\hline Multi Target Push Accuracy Test & .829 & & & & & & & .766 \\
\hline 'D'Pushing Accuracy Test & & & & & & & .784 & .681 \\
\hline Multi Side Passing Accuracy Test & & .726 & & & .301 & & & .767 \\
\hline $\begin{array}{c}\text { One Touch Accurate Cone Passing } \\
\text { Test }\end{array}$ & .305 & & & & & & & .695 \\
\hline Accurate Interchange Passing Test & & & & -.410 & & & & .528 \\
\hline Eigen values & 1.816 & 1.518 & 1.386 & 1.300 & 1.203 & 1.096 & 1.093 & \\
\hline$\%$ of Variance Explained & 12.107 & 10.122 & 9.243 & 8.670 & 8.018 & 7.306 & 7.289 & \\
\hline Cumulative \% & 12.107 & 22.229 & 31.471 & 40.141 & 48.159 & 55.466 & 62.755 & \\
\hline
\end{tabular}

\section{$\mathbf{F}=$ Factor}

The Eigen values (latent roots), percentage variance and cumulative percentage of variance pertaining to rotated factor matrix were given in the table. There are various indicators, which are used by researchers to decide on the number of factors that need to be extracted. Thus it was imperative to decide on the indicator and the level of indicator, which should be considered the cut-off to decide on the number of factors to be extracted. Kaiser (1959) measure a statistical adequacy was one such measure, which signifies the extent to which every variable can be predicted by all other variables and it was widely believed that an overall measure of 0.80 or higher was very good, though a measure of under 0.50 was considered as poor, above the value of 0.50 which was set as the upper value for extraction.

\section{A. FACTOR I}

The Factor I of the factor analysis shows that only two test items has emerged in factor one. They were Multi Target Push Accuracy Test which has a loading of 0.82 and One Touch Accurate Cone Passing Test which has a loading of 0.30 .

The push stroke is work-horse of modern Hockey because, it enables a player travelling at any speed to deftly pass the ball in any desired direction instantly without prior indication of the direction or timing of the pass. Although the stroke lacks the power possible with hit, good players at senior level can easily push a ball seventy five meters. Multi target Push Accuracy Test indicates the importance of accuracy related ability of the player. Hence the best suited name for this factor is "Passing Accuracy Factor".

\section{B. FACTOR II}

The Factor II of the factor analysis shows that only two test items has emerged in factor two. They were 'W' Zig-Zag Cone Dribbling Test which has a loading of 0.68 and Multi Side Passing Test which has a loading of 0.72 .

Speed dribble which is used for open field runs with the ball. The dribbling technique contains several common elements found in ball-control movements. In addition to the close control of the ball, these include sudden change of direction of speed, body swerves and fakes and deceptive side steps. Inside attack players need close stick work and dribbling techniques because of the frequently encountered tight spaces. The outside attack players have more open space often uses the dribbling skill.

To keep the possession of the ball longer than player skills, a defender will surely take it away to pass the ball. The pass will help to move the ball up the field, avoiding opposing players, and score goals. The factor indicates importance of technique involved in passing and dribbling accuracy, hence the best suited name for this factor is "Dribble \& Pass Accuracy Factor", as the selected tests are all together measuring the dribbling and passing ability of a hockey player. 


\section{FACTOR III}

The Factor III of the factor analysis shows that only two test items has emerged in this factor. They were Multi Target Hitting Test which has a loading of 0.63 and Long Distance Hitting Accuracy Test which has a loading of -0.74. The hit is used to score more often than any other Hockey passing technique. There are many situations during a game when maximizing the speed of the ball is more important than disguising the intention to deliver it. Hit indicates the importance of accuracy related ability of a player. Hence the best suited name for this factor is "Hitting Accuracy Factor.

D. FACTOR IV

The Factor IV of the factor analysis shows that only two test items has emerged in his factor one. They were Restricted Area Stopping Test which has a loading of 0.83 and Accurate Interchange Passing Test which has a loading of - 0.41 . The test item Accurate Interchange Passing test has a loading less than 0.50 and hence was not considered. Stopping is used to restrict the movement of an oncoming ball to bring it complete control in such way, that the ball comes to a place from where the next possible stroke can be executed without wasting time. Stopping is the most valuable weapon in defense to avoid more goal scoring and to stop the penetration by the opponents. The factor indicates importance of technique involved in stopping accuracy, hence the best suited name for this factor is "Controlled Stopping Factor".

\section{E. FACTOR $V$}

The Factor $\mathrm{V}$ of the factor analysis shows that only two test items has emerged in factor five. They were Multi Side Stopping Accuracy Test which has a loading of 0.81 and Multi Side Passing Accuracy Test which has a loading of -0.30 . The test item Multi Side Passing Accuracy test has a loading less than 0.50 and hence was not considered. Stopping depends largely upon the receiver's intention for the next move. Players can make use of trapping ability in almost every phase of the game. To trap means to stop the ball with one's stick to make the ball to come to a halt during motion as desired. Perfect trapping can help the players to keep possession of the ball, to build up the attack, to defend from the attack, to stop goal scoring by the opponent, to re-start the game due to infringements and receiving passes from own teammate. The factor indicates importance of technique involved in stopping accuracy, hence the best suited name for this factor is "Trapping Accuracy Factor".

\section{F. FACTOR VI}

The Factor VI of the factor analysis shows that only two test items has emerged in this factor. They were Goal Stopping Accuracy Test which has a loading of 0.71 and Straight Zig-Zag Cone Dribble Test which has a loading of -0.30 . The test item Straight Zig-Zag Cone Dribble Test has a loading less than 0.50 and hence were not considered for testing the skill. Stopping is the most valuable weapon in defense to avoid more goal scoring and to stop the penetration by the opponents. The skill of stopping is the most necessary to block or to check the opponents attack and in this case, the defender block the opponents attack and also brings the ball under control to rebuild his own attack or to change the opponent's attack to defense. The factor indicates importance of technique involved in stopping and dribbling accuracy, hence the best suited name for this factor is "Goal Stopping Factor".

\section{G. FACTOR VII}

The Factor VII of the factor analysis shows that only two test items has emerged in factor seven. They were ' $D$ ' Hitting Accuracy Test which has a loading of 0.42 and 'D' Pushing Accuracy Test which has a loading of 0.78 . The test item ' $D$ ' Hitting Accuracy Test has a loading less than 0.50 and hence were not considered for testing the skill. Pushing is one of the good skills many players use in the game. Players use this skill when they want to pass the ball to his own team or to score a goal and it is easy for the receiver to collect the ball and get possession of the ball whenever his teammates uses the push and the ball travels along the ground. Push stroke is more advantage in penalty corner and penalty stroke. The factor indicates importance of technique involved in pushing accuracy, hence the best suited name for this factor could be "Pushing Accuracy Factor".

TABLE No. 3

Variables Representing the Selected Factors to Construct Skill Tests for Female Hockey Players

\begin{tabular}{|c|c|c|c|}
\hline S. No. & Factor Number & Factor Name & Highest Loaded Variables \\
\hline 1 & Factor I & Passing Accuracy Factor & Multi Target Push Accuracy Test \\
\hline \multirow[t]{2}{*}{2} & \multirow[t]{2}{*}{ Factor II } & \multirow[b]{2}{*}{ Dribble \& Pass Accuracy Factor } & 'W' Zig-Zag Cone Dribbling Test \\
\hline & & & Multi Side Passing Accuracy Test \\
\hline 3 & Factor III & Hitting Accuracy Factor & Multi Target Hitting Test \\
\hline 4 & Factor IV & Controlled Stopping Factor & Restricted Area Stopping Test \\
\hline 5 & Factor V & Trapping Accuracy Factor & Multi Side Stopping Accuracy Test \\
\hline 6 & Factor VI & Goal Stopping Factor & Goal Stopping Accuracy Test \\
\hline 7 & Factor VII & Pushing Accuracy Factor & 'D' Pushing Accuracy Test \\
\hline
\end{tabular}

Finally norms were developed using percentiles and Hull scale. All the individual performance of the skill test was converted as composite score. Based on the norms, a Hull scale, i.e. 2 standard deviations above and 
below the mean was developed to calculate the playing ability scores. Finally from the norms a grading scale was developed to interpret the playing ability of the players for 8 selected skills test items for female field hockey players age ranged from 17 to 25 years.

TABLE No. 4

Hull Scale Norms for Selected Skills Tests for Female Hockey Players

\begin{tabular}{|c|c|c|c|c|c|}
\hline HULL SCALE & $2 \sigma$ & $1 \sigma$ & 0 & $-1 \sigma$ & $-2 \sigma$ \\
\hline ALPHABETICAL GRADES & $\mathbf{A}$ & B+ & B & $\mathbf{C}$ & D \\
\hline $\begin{array}{l}\text { INTERPRETATIVE } \\
\text { GRADES }\end{array}$ & GOOD & $\begin{array}{c}\text { ABOVE } \\
\text { AVERAGE }\end{array}$ & AVERAGE & $\begin{array}{c}\text { BELOW } \\
\text { AVERAGE }\end{array}$ & POOR \\
\hline \multicolumn{6}{|c|}{ PLAYING ABILITY PERFORMANCE SCORES } \\
\hline $\begin{array}{c}\text { Multi Target } \\
\text { Push Accuracy Test }\end{array}$ & More than 21 & $>16 \& \leq 21$ & 8 to 15 & $<7 \& \geq 2$ & Less Than 2 \\
\hline $\begin{array}{l}\text { Multi Side Passing } \\
\text { Accuracy Test }\end{array}$ & More than 20 & $>16 \& \leq 20$ & 9 to 15 & $<8 \& \geq 3$ & Less than 3 \\
\hline $\begin{array}{c}\text { 'W' Zig-Zag Cone } \\
\text { Dribble Test }\end{array}$ & More than 30 & $>23 \& \leq 30$ & 14 to 22 & $<13 \& \geq 6$ & Less than 6 \\
\hline $\begin{array}{c}\text { 'D' Hitting Accuracy } \\
\text { Test }\end{array}$ & More than 15 & $>12 \& \leq 15$ & 8 to 11 & $<10 \& \geq 4$ & Less than 4 \\
\hline $\begin{array}{c}\text { Restricted Area Stopping } \\
\text { Accuracy Test }\end{array}$ & - & More than 3 & 2 to 3 & Less than 2 & - \\
\hline $\begin{array}{c}\text { Multi Side Stopping } \\
\text { Accuracy Test }\end{array}$ & More than 8 & $>6 \& \leq 8$ & 3 to 5 & $<4 \& \geq 2$ & Less than 2 \\
\hline $\begin{array}{c}\text { Goal Stopping Accuracy } \\
\text { Test }\end{array}$ & - & More than 6 & 4 to 6 & Less than 4 & - \\
\hline $\begin{array}{c}\text { 'D' Pushing Accuracy } \\
\text { Test }\end{array}$ & More than 19 & $>15 \& \leq 19$ & 9 to 14 & $<8 \& \geq 4$ & Less than 4 \\
\hline
\end{tabular}

\section{Conclusions}

1. The result reveals that there was inter-relationship between the performances of selected test items.

2. Total eight test items from the seven factors which had high loading were selected to constitute the 'Field Hockey Skill Tests' for the female field hockey players. The seven factors were emerged with the different skills tests describing player specific skill ability. The name of the factor and the loaded skill tests are as follows:

a. Multi Target Push Accuracy test was loaded in the Passing Accuracy Factor.

b. Multi Side Passing Accuracy Test and 'W' Zig-Zag Cone Dribbling Test were the highest loaded tests in Dribble \& Pass Accuracy Test.

c. Multi Target Hitting Accuracy Test was loaded in the Hitting Accuracy Factor.

d. Restricted Area Stopping Test was loaded in the Controlled Stopping Factor.

e. Multi Side Stopping Accuracy Test was loaded in the Controlled Stopping Factor.

f. Goal Stopping Accuracy Test was loaded with the highest value more than 0.500 in the Trapping Accuracy Factor.

g. 'D' Pushing Accuracy test was loaded in the Pushing Accuracy Factor

3. The playing ability performance (overall performance) score of the players were interpreted by using grading scale on the basis of Hull Scale as A, B+, B, C \& D (or) Good, Above Average, Average, Below Average \& Poor respectively according to their overall performance score based on the percentiles norm, which was developed for all the selected test items.

\section{References}

1. E. C. D, "The Development of Multi Skill Test in Lacrose for College Women" in A Practical Approach to Measurement in Physical Education Henry Kimpton Publisher London, Great Britain: H. M. McGee, 1979, pp. 275-278.

2. J. Edwards, "A Study of Three Measures of the Tennis Serve" in A Practical Approach to Measurement in Physical Education, $3^{\text {rd }}$ ed., Henry Kimpton Publisher London, Great Britain: H. M. McGee, 1979, pp. 303305.

3. H.V, "The How to Teach Badminton from Players to Teacher." in A Practical Approach to Measurement in Physical Education, $3^{\text {rd }}$ ed., Henry Kimpton Publisher London, Great Britain: H. M. McGee, 1979, pp. 215.

4. F. A. Miller, "A Badminton Wall Volley Test." in A Practical Approach to Measurement in Physical Education, $3^{\text {rd }}$ ed., Henry Kimpton Publisher London, Great Britain: H. M. McGee, 1979, pp. 223-224. 
5. K. Petry, "Evaluation of a Volleyball Serve Test." in A Practical Approach to Measurement in Physical Education, $3^{\text {rd }}$ ed., Henry Kimpton Publisher London, Great Britain: H. M. McGee, 1979, pp. 312-314

6. H.Singh, "Hockey Through Testing." in A Practical Approach to Measurement in Physical Education, $3^{\text {rd }}$ ed., Henry Kimpton Publisher London, Great Britain: H. M. McGee, 1979, pp. 250-257.

7. H. C.Stubbs, "An Exploratory Study in Girls: Basketball Relative to the Measurement of Ball Handling Ability." in A Practical Approach to Measurement in Physical Education, $3^{\text {rd }}$ ed., Henry Kimpton Publisher London, Great Britain: H. M. McGee, 1979, pp. 231-233.

8. A. W. Kronqvist, "A Modification of the Brady Volleyball Skill Test for High School Boys." in A Practical Approach to Measurement in Physical Education, $3^{\text {rd }}$ ed., Henry Kimpton Publisher London, Great Britain: H. M. McGee, 1979, pp. 314-315.

9. A. C. Farrow, "Skill and Knowledge Proficiences for Selected Activities in the Required Progam at Memphis State University." in A Practical Approach to Measurement in Physical Education, $3^{\text {rd }}$ ed., Henry Kimpton Publisher London, Great Britain: H. M. McGee, 1979, p. 214.

10. A. C. G, “Achievement Examination in Badminton." in A Practical Approach to Measurement in Physical Education, $3^{\text {rd }}$ ed., Henry Kimpton Publisher London, Great Britain: H. M. McGee, 1979, pp. 221-222

11. S.G, "Speedball Skill Tests for College Women." in A Practical Approach to Measurement in Physical Education, $3^{\text {rd }}$ ed., Henry Kimpton Publisher, London, Great Britain: H. M. McGee, 1979, p. 371.

12. A.A.Lockhart, "The Development of a Test of Badminton Playing Ability." in Textbook of Applied Measurement,Evaluation and Sports Sciences, $2^{\text {nd }}$ ed., SSS Publications, New Delhi, India: D. K. Kansal, 2008, pp. 391-392.

13. AAPHER, "Basketball Skill Test Manual for Boys." in Textbook of Applied Measurement,Evaluation and Sports Sciences, $2^{\text {nd }}$ ed., SSS Publications, New Delhi, India: D. K. Kansal, 2008, pp. 360-361.

14. C. C, "A Study of Measurement of Ability in Handball." in Textbook of Applied Measurement,Evaluation and Sports Sciences, $2^{\text {nd }}$ ed., SSS Publications, New Delhi, India: D. K. Kansal, 2008, pp. 364-365.

15. M.A.Clifton, "Single Hit Volley Test for Women Volleyball." in Textbook of Applied Measurement,Evaluation and Sports Sciences, $2^{\text {nd }}$ ed., SSS Publications, New Delhi, India: D. K. Kansal, 2008, p. 377.

16. B.G.F,"Premilinary Investigations Volleyball Playing Ability." in Textbook of Applied Measurement,Evaluation and Sports Sciences, $2^{\text {nd }}$ ed., SSS Publications, New Delhi, India: D. K. Kansal, 2008, pp. 376-377.

17. R.D.Knox, "Basketball Ability Tests." in Scholastics Coach, 17 (3), 1947, pp. 19-21.

18. R.Singh, "Construction of Soccer Playing Ability Test," Unpublished Doctorate Thesis, Department of Teacher Education, Lakshmibai National University of Physical Education, Gwalior, Utter Pradesh, Ph.D. dissertation, 2002.

19. R.K.Viswanathan,., "Construction of Hockey Skill selected skill tests for Tamil Nadu School Boys for Fourteen and Sixteen Years.", Ph.D. dissertation, Department of physical education, Manonmaniam Sundaranar University, Tamil Nadu, Ph.D,2010.

20. D. K. Dureha, "Construction of an objective skill test in hockey", Unpublished M.Phil. Thesis, Department of physical education, University of Pune, Pune, M. Phil (1985).

21. Friedel Jean Elizabeth ,'The development of a field hockey skill test for high school girls", Unpunlished Master's Thesis, School of Health, Physical Education and Recreation, University of Oregon, M.S. Illinois State Normal University 1956.

22. P. Anbarasu," Construction of Skill Tests and Computation of Norms in Field Hockey", Unpublished dissertation of Doctor of Philosophy, Department of physical education, Tamil Nadu Physical Education and Sports University, Tamil Nadu, Ph.D, 2010.

23. A.P.Aver, "A Practical Tennis Serve Test, Measurement of Skill under Stimulated Game Condition" Research Quaterly for Exercise \& Sports Sciences, vol.50, issue 4, 1979, pp.554-564.

24. N.L.Chapman, "Chapman Ball Control Test- Field Hockey" Research Quaterly for Exercise and Sport, vol. 53, issue 3, 1982, pp. 239-242.

25. T.M.Downs, "Validating a Special Olympics Volleyball Skills Assessment Test" APAQ, vol. 13, issue 2, 2008, pp. 166-179.

26. M.S.French, "Achievement Test in Field Hockey for College Women”, Research Quaterly For Exercise \& Sport, vol. 34, issue 84, 1940.

27. G.B.Gabbett, "The Development of a Standardized Skill Assessment for Junior Volleyball Players", Inetrnational Journal of Sports Physiological Performance, vol.1, issue 2, 2006, pp. 95-107.

28. M.T.Gemser, "Development of the Tactical Skills Inventory for Sports, Perceptual and Motor Skills", International Journal of Sports Sciences, vol.3, issue 3, 2003, pp. 883-895.

29. W.B.Hensley, "A Racquetball Skills Test”, Research Quaterly for Exercise and Sports Sciences, vol. 50, issue 1, 1973, pp. 114-118. 
30. D.R.Hopkins, "Using Skill Tests to Identify Successfull and Unsuccessful Basketball Performers", Research Quarterly for Exercise and Sports Sciences, 1977, 381-387.

31. J.A.Illner, "The Construction and Validation of a Skill test for the Drive in Field Hockey", Completed Reserach in Health, Physical Education and Recreation, vol.3, 1969, p.200.

32. M.B.Isaacs, "An Improved Racquetball Skills Test", Research Quarterly for Exercise and Sports Sciences, vol. 50, issue 3, 1979, 526-527.

33. G.B.Solomon, "The Assessment of Athletic Ability in Intercollegiate Sports: Instrument Construction and Validation", International Journal of Sports Medicine and Coaching, vol.3, issue 4, 2008, p.11.

34. C.J.Strait, "The Construction and Evaluation of a Field Hockey Skill test", Completed Research Health Physical Education and Recreation, vol.3, issue 68, 1961.

35. T.C.Zhang, "Development and Validation of a Racquetball Skill Selected skill tests for Young Adult Beginners", Journal of Measurement in Physical Education \& Exercise Science, vol.6, issue 2, pp.95-126. 